\title{
Pericardioesophageal Fistula
}

\author{
Amr Mohamed ${ }^{1}$ \\ ${ }^{1}$ Rochester General Hospital
}

May 22, 2021

\begin{abstract}
Chest pain immediately after atrial fibrillation ablation is seen essentially with every case, and we counsel the patients that it is expected. On the other hand, delayed chest pain is not always expected and usually points towards a procedure complication, as shown in this case.
\end{abstract}

Title : pericardioesophageal fistula

Author : Mohamed Amr, MD

Affiliation : Department of Internal Medicine, Rochester General Hospital, Rochester, NY.

Corresponding Author: Mohamed Amr, MD

Contact number : 718-764-7202

Affiliation Address : 1425 Portland Avenue, Rochester, NY, 14621.

Email address : amrelwagdycardiol@gmail.com

Funding source : none

Conflict of interest : none

Article type : Clinical image

Word count excluding references : 179

This is a 70-year-old-year-old female with a past medical history of atrial fibrillation. Underwent atrial fibrillation ablation procedure two weeks ago. She is now presenting with pericardial chest pain and dysphagia two weeks after the ablation procedure. Her vital signs are normal, and her physical exam is unrevealing.

CT scan of the chest showed pneumopericardium with evidence of pericardioesophageal fistula. She underwent pericardial window and oesophageal stenting, and her postoperative course was uneventful.

From this case, the critical clinical message is to know that Late-onset chest pain, dysphagia, or endocarditislike symptoms post atrial fibrillation ablation could be an alarm for fatal complications as Esophagoatrial or Pericardioesophageal fistula. If the diagnosis is delayed, mortality is inevitable. Having a high index of suspicion is the key to early diagnosis. 


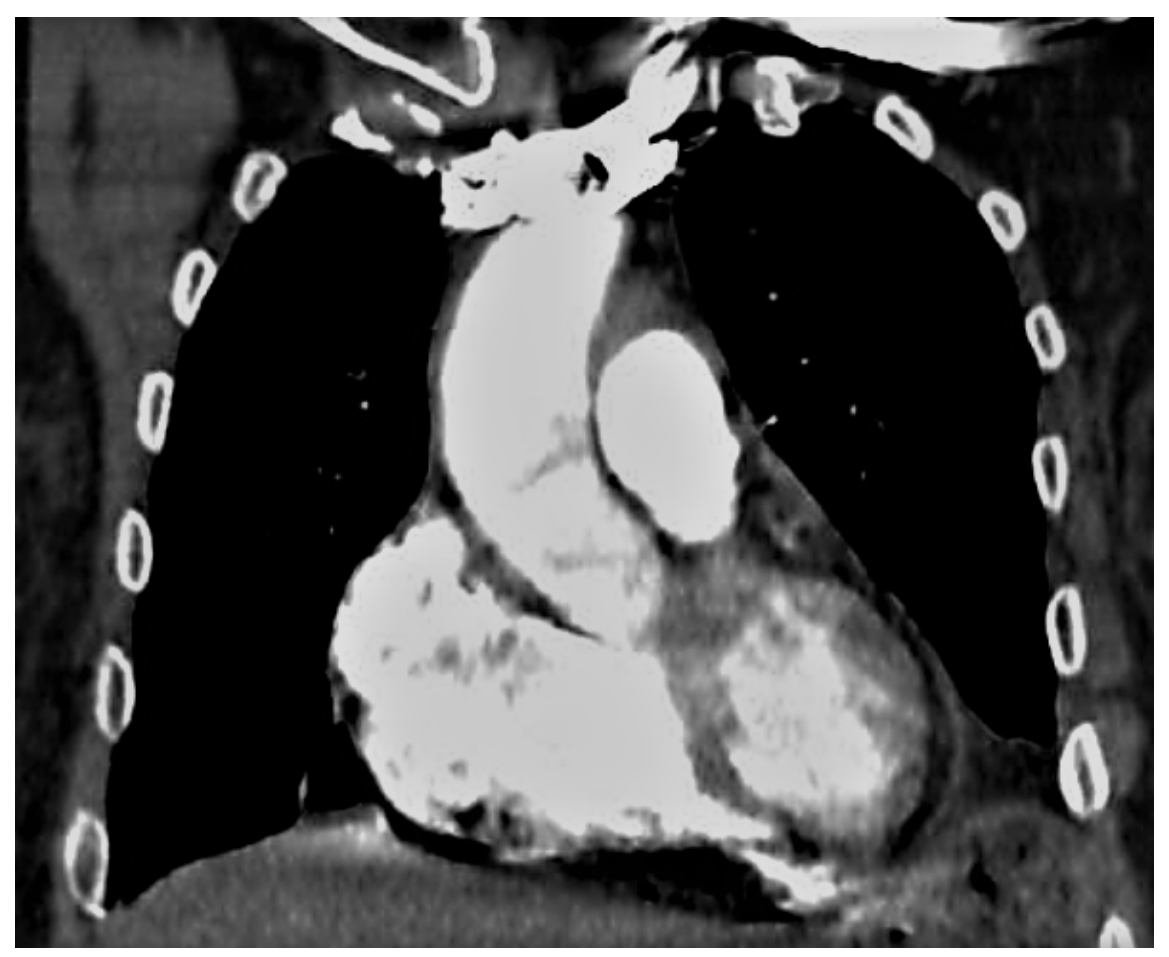

